\title{
Deposition Characteristics of Firebrands on and Around Rectangular Cubic Structures
}

\author{
Aditya Mankame and Babak Shotorban* \\ Department of Mechanical and Aerospace Engineering, The University of Alabama in Huntsville, Huntsville, AL, United States
}

OPEN ACCESS

Edited by:

Naian Liu,

University of Science and Technology

of China, China

Reviewed by:

Wei Tang,

National Institute for Occupational

Safety and Health (NIOSH),

United States

Xinyan Huang,

Hong Kong Polytechnic University,

Hong Kong

*Correspondence:

Babak Shotorban

babak.shotorban@uah.edu

Specialty section:

This article was submitted to

Thermal and Mass Transport,

a section of the journal

Frontiers in Mechanical Engineering

Received: 12 December 2020

Accepted: 17 May 2021

Published: 10 June 2021

Citation:

Mankame A and Shotorban B (2021)

Deposition Characteristics of

Firebrands on and Around Rectangular

Cubic Structures.

Front. Mech. Eng 7:640979.

doi: 10.3389/fmech.2021.640979
The focus of the present work is on the deposition of firebrands in a flow over a rectangular cubic block representative of a structure in wildland-urban interface (WUI). The study was carried out by physics based modeling where the wind flow turbulence was dealt with by large eddy simulation (LES) and firebrands were treated by Lagrangian tracking. The Lagrangian equations coupled with the flow solver, accounted for both translational and rotational motions as well as thermochemical degradation of firebrands, assumed to be cylindrical. The dimensions of the structure were varied from 3 to $9 \mathrm{~m}$ in the simulations for a parametric study. The simulations were carried out by tracking many firebrands randomly released with a uniform distribution from a horizontal plane $35 \mathrm{~m}$ above the ground into the computational domain. The coordinates of the deposited firebrands were used to calculate their normalized number density (number of landed firebrands per unit surface area) to quantify their deposition pattern. On the leewardside of the block, an area, referred to as the safe zone, was identified right behind the structure where firebrands never deposit. The size of the safe zone in the direction perpendicular to the wind was nearly identical to the width of the structure. The length of the safe zone in the wind direction was proportional to the height of the structure. The leeward face of the blocks was never hit by a firebrand. The windward face was hit by many more firebrands than the lateral faces but much less than the top face. The distribution of the number density of the deposited firebrands on the top face was found to be correlated with the flow separation and reattachment on this face.

Keywords: firebrands, flow over a block, large eddy simulation, firebrand deposition, WUI fire, Lagrangian tracking

\section{INTRODUCTION}

A critical mechanism for the spread of large outdoor fires, e.g., wildland-urban interface (WUI) fires is spotting. Spotting is the creation of the secondary (spot) fires by firebrands that are generated by the primary fires. Firebrands can be lofted up into the atmosphere and carried away by the ambient wind to short/long distances (Tarifa et al., 1967; Sardoy et al., 2008). In the presence of strong ambient winds, firebrands can cross distances from a few $100 \mathrm{~m}$ to a few kilometers, thus capable of spreading fires over barriers such as rivers, lakes, hills, etc. Spotting is seen frequently in WUI fires and can burn down many WUI structures under extreme conditions such as an ember shower (Manzello, 2014). This motivated the present computational study with a focus on characterizing the deposition pattern of firebrands carried by the wind on top and in the vicinity of a structure shaped as a rectangular cuboid mounted on the ground. The computational configuration here can be considered as a simplified representation of a single isolated WUI structure. 
There have been several studies on the role of firebrands in the spread of wildland and WUI fires. Manzello et al. (2007) performed experiments by burning two Douglas-fir trees with 2.6 and $5.2 \mathrm{~m}$ heights. They found that the generated firebrands were predominately cylindrical in shape with an average diameter of $3 \mathrm{~mm}$ and length of $40 \mathrm{~mm}$ for the shorter tree and 4 and $53 \mathrm{~mm}$ for the taller tree. Manzello et al. (2008) constructed an apparatus capable of generating glowing firebrands and used it to release firebrand in a wind tunnel. The firebrands released in the wind-tunnel at $9 \mathrm{~m} / \mathrm{s}$ experienced a mass loss of $20-40 \%$ when compared to firebrands released in no wind condition. Tohidi and Kaye (2017b), Tohidi and Kaye (2017a) experimentally and computationally studied the lofting of firebrands in a wind tunnel where in addition to wind, a convective plume was included. They observed that for higher wind speeds, the change in the initial vertical velocity of the convective column did not affect the mean or standard deviation of the heights where the firebrands lofted or the distances they traveled to land. Yin et al. (2003), Oliveira et al. (2014) developed numerical models for the firebrand transport accounting for the drag, lift and gravitational forces and their effect on the rotation of firebrands to model both translational and rotational motions of cylindrical firebrands. To validate their model, Oliveira et al. (2014) performed computations and experiments for a cylindrical firebrand (balsa wood) falling from an elevated point under a no ambient flow condition. The influence of different formulations for the distance between center of pressure and center of mass of a cylindrical object in motion was explored in the modeling by Rayleigh (1876), Marchildon et al. (1964), Rosendahl (2000), Yin et al. (2003).

Anand et al. (2018) preformed simulations to investigate the deposition of cylindrical firebrands released in a turbulent wind environment from a fixed elevated point. They assumed for firebrands to retain their mass from release to landing. They reported a bivariate Gaussian function like distribution for the landed firebrand position with a larger variance in the streamwise direction, compared to the spanwise direction. Anand (2018) performed similar simulations while allowing firebrands to experience mass loss due to thermal degradation, taking into account the effect of burning. They observed that, firebrands with a higher mass density $\left(570 \mathrm{~kg} / \mathrm{m}^{3}\right)$ experienced a higher mass loss, as compared to lower density $\left(230 \mathrm{~kg} / \mathrm{m}^{3}\right)$ firebrands. The lower density firebrands cooled rapidly and reached ambient temperature before landing. On the other hand, the higher density firebrands retained more thermal energy while flying, thus had higher temperatures at landing. Song et al. (2017) performed wind tunnel experiments with disc-shape firebrands and showed the deposited firebrands had uni-modal distribution except for certain wind speed and firebrand conditions where they displayed a bimodal distribution.

Properties of the flow over a cubic obstacle mounted on the ground have been studied in the past (Murakami et al., 1987; Werner and Wengle, 1993; Lee and Bienkiewicz, 1997; Rodi, 1998). One of the earliest works is due to Murakami et al. (1987) who simulated a cube submerged in a boundary layer using largeeddy simulation (LES). Werner and Wengle (1993), Rodi (1998) computationally studied a cube mounted on a surface in a channel flow with a Reynolds number of $O\left(10^{4}\right)$ based on the velocity at the height of the cube. Werner and Wengle (1993), Rodi (1998) showed the existence of a horse-shoe vortex on the windward side of the cube and flow separation and reattachment on the top face of the cube. Rodi (1998), using different turbulence models, reported two counter rotating recirculation region on the leeward side of the cube. Vortex shedding was observed originating from the lateral faces with a pair of re-circulation region closer to these faces. More recently, Richards et al. (2001) claimed the pressure coefficient on the surface of the cube is independent of the Reynolds number via a field test. Later in wind-tunnel experiments (Richards et al., 2007), they observed a drop in the pressure coefficient on the windward and leeward faces of the cube as the wind direction changed from $90^{\circ}$ to $45^{\circ}$ with respect to the windward face of the cube. Lim et al. (2009) performed experiments and simulations for a flow around a cube submerged in a turbulent atmospheric surface layer (ASL) and showed that the mean profiles of pressure coefficient and velocity components are independent of the Reynolds number.

The present work is a modeling study focused on deposition of firebrands in a flow over a cubic block representative of a structure in WUI. The flow is dealt with by LES while the deposition of firebrands is treated in the Lagrangian framework. In Section 2, modeling approaches are illustrated for both firebrands and the flow. In Section 3, results are presented with the model validation results included. Concluding remarks are made in Section 4.

\section{MODELING APPROACHES}

\subsection{Firebrand Equations}

The firebrand equations are expressed and solved in the Lagrangian framework. Firebrands are assumed to be cylinders with a large ratio of length to diameter, undergoing both translational and rotational motions (Yin et al., 2003; Oliveira et al., 2014; Anand et al., 2018) and thermal degradation as a result of pyrolysis and charring (Morvan and Dupuy, 2004; Anand, 2018).

\subsubsection{Translational Motion}

The position and velocity of the center of mass of the firebrand are denoted by $\vec{x}_{\mathrm{p}}$ and $\vec{V}_{\mathrm{p}}$, respectively, which are governed by

$$
\begin{gathered}
\frac{d \vec{x}_{\mathrm{p}}}{d t}=\vec{V}_{\mathrm{p}}, \\
m_{\mathrm{p}} \frac{d \vec{V}_{\mathrm{p}}}{d t}=\vec{F}_{\mathrm{G}}+\vec{F}_{\mathrm{D}}+\vec{F}_{\mathrm{L}}
\end{gathered}
$$

where $d / d t$ is the time derivative calculated in the Lagrangian framework. Eq. 2 is an expression of Newton's second law where the forces are due to gravity combined with buoyancy $\vec{F}_{\mathrm{G}}$, drag $\vec{F}_{\mathrm{D}}$ and lift $\vec{F}_{\mathrm{L}}$, which are calculated (Hoerner, 1965) by:

$$
\vec{F}_{\mathrm{G}}=\left(\rho_{\mathrm{p}}-\rho_{\text {gas }}\right) \mathcal{V} \vec{g}
$$




$$
\begin{gathered}
\vec{F}_{\mathrm{D}}=\frac{1}{2} C_{\mathrm{D}} \rho_{\text {gas }} D_{\mathrm{p}} l\left|\vec{V}_{\text {rel }}\right||\sin \alpha|^{3} \vec{V}_{\text {rel }} \\
\vec{F}_{\mathrm{L}}=\frac{1}{2} C_{\mathrm{D}} \rho_{\text {gas }} D_{\mathrm{p}} l\left(\left|\vec{V}_{\text {rel }}\right| \sin \alpha\right)^{2} \cos \alpha \frac{\widehat{z}_{\mathrm{r}} \times \vec{V}_{\text {rel }} \times \vec{V}_{\text {rel }}}{\left|\widehat{z}_{\mathrm{r}} \times \vec{V}_{\text {rel }} \times \vec{V}_{\text {rel }}\right|}, \\
C_{\mathrm{D}}= \begin{cases}\frac{10}{\operatorname{Re}_{\alpha}^{0.778}} & \text { for } \operatorname{Re}_{\alpha} \leq 0.1 \\
\frac{10}{\operatorname{Re}_{\alpha}^{0.778}}\left(1+0.1076 \mathrm{Re}_{\alpha}^{0.778}\right) \\
1.1 & \text { for } 0.1<\operatorname{Re}_{\alpha} \leq 6 \times 10^{3},\end{cases}
\end{gathered}
$$

Here, $\rho_{\mathrm{p}}, D_{\mathrm{p}}, l, \mathcal{V}, m_{\mathrm{p}}$ and $\vec{V}_{\text {rel }}$ are the firebrand density, diameter, length, volume, mass and velocity relative to the flow at the center of mass of the particle, respectively. It is calculated by $\vec{V}_{\text {rel }}(t)=$ $\vec{U}\left[\vec{x}_{\mathrm{p}}(t), t\right]-\vec{V}_{\mathrm{p}}(t)$ where the first term indicates the flow velocity at the position of the center of mass of the firebrand. The drag coefficient $C_{\mathrm{D}}$ is calculated, using the particle Reynolds number $\operatorname{Re}_{\alpha}=D_{\mathrm{p}} \rho\left|\vec{V}_{\text {rel }}\right| \sin \alpha / \mu$ (Kelbaliyev, 2011), where $\rho_{\text {gas }}$ is the density of air and $\alpha$ is the incidence angle between the relative velocity and the major axis of the cylindrical firebrand $\widehat{z}_{\mathrm{r}}$.

\subsubsection{Rotational Motion}

The rotational motion is described by the Euler rotation equation:

$$
\begin{aligned}
& I_{x^{\prime}} \frac{d \omega_{x^{\prime}}}{d t}-\omega_{y^{\prime}} \omega_{z^{\prime}}\left(I_{y^{\prime}}-I_{z^{\prime}}\right)=T_{x^{\prime}}^{\prime}, \\
& I_{y^{\prime}} \frac{d \omega_{y^{\prime}}}{d t}-\omega_{z^{\prime}} \omega_{x^{\prime}}\left(I_{z^{\prime}}-I_{x^{\prime}}\right)=T_{y^{\prime}}^{\prime}, \\
& I_{z^{\prime}} \frac{d \omega_{z^{\prime}}}{d t}-\omega_{x^{\prime}} \omega_{y^{\prime}}\left(I_{x^{\prime}}-I_{y^{\prime}}\right)=T_{z^{\prime}}^{\prime},
\end{aligned}
$$

where $I_{x^{\prime}}, I_{y^{\prime}}$ and $I_{z^{\prime}}$ are the moments of inertia with respect to the Cartesian frame of reference $x^{\prime}-y^{\prime}-z^{\prime}$ attached to the cylindrical firebrand with the origin at the cylinder center and the $z^{\prime}$ axis constituting the cylinder axis. The total torque is the addition of the torque $\vec{T}_{\text {hydro }}^{\prime}$ due to the hydrodynamic forces and the torque $\vec{T}_{\text {resist }}^{\prime}$ (Oliveira et al., 2014) due to the frictional air resistance experienced by the firebrand

$$
\begin{gathered}
\vec{T}^{\prime}=\vec{T}_{\text {hydro }}^{\prime}+\vec{T}_{\text {resist }}^{\prime} \\
\vec{T}_{\text {resist }}^{\prime}=\sqrt{\left(T_{\text {resist }}^{x^{\prime}}\right)^{2}+\left(T_{\text {resist }}^{y^{\prime}}\right)^{2}}, \\
T_{\text {resist }}^{x^{\prime}}=-\rho_{\text {gas }}\left|\omega_{x^{\prime}}\right| a b^{4}\left[0.538+3.62\left(\frac{\rho_{\text {gas }} a\left|\omega_{x^{\prime}}\right| b}{\mu}\right)^{-0.778}\right] \omega_{x^{\prime}}, \\
T_{\text {resist }}^{y^{\prime}}=-\rho_{\text {gas }}\left|\omega_{y^{\prime}}\right| a b^{4}\left[0.538+3.62\left(\frac{\rho_{\text {gas }} a\left|\omega_{y^{\prime}}\right| b}{\mu}\right)^{-0.778}\right] \omega_{y^{\prime}}, \\
\vec{T}_{\text {hydro }}^{\prime}=x_{\mathrm{cp}} \mathbf{A} \cdot\left[\widehat{z}_{\mathrm{r}} \times\left(\vec{F}_{\mathrm{D}}+\vec{F}_{\mathrm{L}}\right)\right], \\
x_{\mathrm{cp}}=l(90-\alpha) / 480 .
\end{gathered}
$$

Here, $a=D_{\mathrm{p}} / 2$ is the radius of the firebrand, $b=l / 2$ is the half length and $x_{\mathrm{cp}}$ is the distance between the center of pressure and the center of mass (Marchildon et al., 1964), and $\mathbf{A}$ is the transformation matrix expressed in terms of quaternions $\epsilon_{1}, \epsilon_{2}, \epsilon_{3}$ and $\eta$ (Yin et al., 2003):

$$
\mathbf{A}=\left[\begin{array}{lll}
1-2\left(\epsilon_{2}^{2}+\epsilon_{3}^{2}\right) & 2\left(\epsilon_{1} \epsilon_{2}+\epsilon_{3} \eta\right) & 2\left(\epsilon_{1} \epsilon_{3}-\epsilon_{2} \eta\right) \\
2\left(\epsilon_{2} \epsilon_{1}-\epsilon_{3} \eta\right) & 1-2\left(\epsilon_{3}^{2}+\epsilon_{1}^{2}\right) & 2\left(\epsilon_{2} \epsilon_{3}+\epsilon_{1} \eta\right) \\
2\left(\epsilon_{1} \epsilon_{3}+\epsilon_{2} \eta\right) & 2\left(\epsilon_{3} \epsilon_{2}-\epsilon_{1} \eta\right) & 1-2\left(\epsilon_{1}^{2}+\epsilon_{2}^{2}\right)
\end{array}\right]
$$

Quaternions are governed by

$$
\frac{d}{d t}\left[\begin{array}{c}
\epsilon_{1} \\
\epsilon_{2} \\
\epsilon_{3} \\
\eta
\end{array}\right]=\frac{1}{2}\left[\begin{array}{c}
\eta \omega_{x^{\prime}}-\epsilon_{3} \omega_{y^{\prime}}+\epsilon_{2} \omega_{z^{\prime}} \\
\epsilon_{3} \omega_{x^{\prime}}+\eta \omega_{y^{\prime}}-\epsilon_{1} \omega_{z^{\prime}} \\
-\epsilon_{2} \omega_{x^{\prime}}+\epsilon_{1} \omega_{y^{\prime}}+\eta \omega_{z^{\prime}} \\
-\epsilon_{1} \omega_{x^{\prime}}-\epsilon_{2} \omega_{y^{\prime}}-\epsilon_{3} \omega_{z^{\prime}}
\end{array}\right] .
$$

The quaternions are correlated with Euler angles $(\phi, \psi, \theta)$ through the following equations, which are used here to find initial values of the quaternions:

$$
\begin{gathered}
\epsilon_{1}=\cos \left(\frac{\phi-\psi}{2}\right) \sin \left(\frac{\theta}{2}\right), \\
\epsilon_{2}=\sin \left(\frac{\phi-\psi}{2}\right) \sin \left(\frac{\theta}{2}\right), \\
\epsilon_{3}=\sin \left(\frac{\phi+\psi}{2}\right) \cos \left(\frac{\theta}{2}\right), \\
\eta=\cos \left(\frac{\phi+\psi}{2}\right) \cos \left(\frac{\theta}{2}\right) .
\end{gathered}
$$

\subsubsection{Mass and Temperature}

Heat is transfered from the firebrand to the surrounding gas through thermal radiation and convection. The firebrand undergoes thermal degradation and loses mass as a result of pyrolysis and char oxidation. To take this effect into account, the firebrand model assumes for the firebrand to be thermally thin (i.e. temperature throughout the firebrand is spatially uniform) with a mass governed by:

$$
\frac{d m_{\mathrm{p}}}{d t}=-\dot{m}_{\mathrm{pyr}}-\dot{m}_{\mathrm{char}}
$$

where $\dot{m}_{\text {pyr }}$ and $\dot{m}_{\text {char }}$ are the mass loss rates due to pyrolysis and char oxidation, respectively, which are modeled by the Arrhenius equation:

$$
\dot{m}_{i}=-m_{i} A_{i} \exp \left(-\frac{T_{i}}{T_{\mathrm{p}}}\right),
$$

where $m_{i}$ represents the mass of the solid constituent, namely $i=$ pyr for the charring of the fuel and char for char oxidation, $A_{i}$ is the pre-exponential factor, $T_{\mathrm{p}}$ is the temperature of the firebrand and $T_{i}=E_{i} / R$ is the activation temperature where $E_{i}$ is the activation energy. The pre-exponential factor and activation temperature for pyrolysis are $A_{\text {pyr }}=725 \mathrm{~s}^{-1}, T_{\text {pyr }}=6899 \mathrm{~K}$ (for Pinus) and for char oxidation are $A_{\text {char }}=430 \mathrm{~m} / \mathrm{s}, \quad T_{\text {char }}=9000 \mathrm{~K}$ (Morvan and Dupuy, 2004; Sardoy et al., 2007; Anand, 2018).

The firebrand temperature is governed by

$$
m_{\mathrm{p}} c_{\mathrm{p}} \frac{d T_{\mathrm{p}}}{d t}=-\Delta h_{\mathrm{pyr}} \dot{m}_{\mathrm{pyr}}-\Delta h_{\mathrm{char}} \dot{m}_{\mathrm{char}}-\dot{q}_{\mathrm{c}}-\dot{q}_{\mathrm{r}}
$$

where $\Delta h_{\mathrm{pyr}}=418 \mathrm{~kJ} / \mathrm{kg}$ and $\Delta h_{\text {char }}=12 \times 10^{3} \mathrm{~kJ} / \mathrm{kg}$ are the enthalpy of pyrolysis and char oxidation, respectively (Sardoy 
et al., 2007; Mell et al., 2009; Anand, 2018). Here, $\dot{q}_{\mathrm{c}}$ and $\dot{q}_{\mathrm{r}}$ are the rates of the convective and radiative heat transfer, respectively:

$$
\begin{aligned}
& \dot{q}_{\mathrm{c}}=h_{\mathrm{c}} A\left(T_{\mathrm{p}}-T_{\infty}\right), \\
& \dot{q}_{\mathrm{r}}=\sigma \epsilon A\left(T_{\mathrm{p}}^{4}-T_{\infty}^{4}\right),
\end{aligned}
$$

where $A$ is the surface area of the firebrand, $T_{\infty}$ is the ambient temperature, $h$ is the heat transfer coefficient, $\sigma$ is the StefanBoltzmann constant and $\epsilon$ is the emmisitivity of the firebrand set to 0.9. It is noted that for improved modeling of the mass loss and thermal energy, combustion models are needed in addition to the char oxidation representation here to more accurately represent the burning effect.

\subsection{Computational Approach}

Our group developed a model that handles the transport and burning of firebrands, according to Eqs. 1-26, in the framework of Fire Dynamic Simulator (FDS, version 6.7.0) (McGrattan et al., 2018). FDS is computational fluid dynamics (CFD) based software capable of modeling the fire dynamics while representing significant thermal, chemical and physical processes such as combustion, turbulence, radiation, etc. In the present study, only the fluid dynamical features of FDS are relevant. Turbulence is dealt with by LES in FDS with the default option of Deardoff model (Deardorff, 1980) set to represent the subgrid-scale (SGS) terms here. FDS uses WallAdapting Local Eddy-viscosity model (WALE) (Nicoud and Ducros, 1999) as the near-wall model by default. The firebrand equations are solved by a second-order AdmasBashforth time integration method, as described by Anand et al. (2018) and Anand (2018). In computations, $\vec{U}\left[\vec{x}_{\mathrm{p}}(t), t\right]$ defined in Section 2.1.1 is calculated via a trilinear interpolation of the flow velocities at cell faces to the location of center of mass of the firebrand. The coupling of firebrands to the flow solver is one-way, as the influence of firebrands on the flow is assumed negligible. The firebrands deposited on the solid surfaces, i.e., ground and faces of the block, are removed from the simulation after their deposition coordinates are recorded.

\section{RESULTS AND DISCUSSION}

\subsection{Firebrand Model Validation}

To validate the firebrand model, first, a firebrand drop test previously investigated both experimentally and computationally (Oliveira et al., 2014) was considered. The exercise involved a non-burning cylindrical firebrand made from balsa wood with diameter $10 \mathrm{~mm}$ and length $80 \mathrm{~mm}$, which was released from the height $8.7 \mathrm{~m}$ in a no-wind condition. At the release point, the firebrand had zero velocities and made an angle of $60^{\circ}$ with the vertical axis. The firebrand mass density was reported $\rho_{\mathrm{p}}=215.5 \mathrm{~kg} / \mathrm{m}^{3}$. Using the firebrand model illustrated in Section 2.1.1 and Section 2.1.2, the drop test was simulated here in a computational domain $1.5 \times$ $1.5 \times 9 \mathrm{~m}$ (length $\times$ width $\times$ height). In lieu of Eq. 15 (Marchildon et al., 1964), other formulas (Table 1) have been also reported in the literature (Rayleigh, 1876; Rosendahl, 2000; Yin et al., 2003) for calculation of $x_{\mathrm{cp}}$. This motivated a sensitivity study of the model to these formulas to be a part of this validation exercise.

Table 1 tabulates the landing times calculated in the current study using various $x_{\mathrm{cp}}$ formulas and compares them against those obtained in the modeling and measurement of Oliveira et al. (2014). Corresponding trajectories of the firebrand from release to landing are shown in Figure 1. Both table and figure suggest the significance of the $x_{\mathrm{cp}}$ formula in the firebrand landing time and trajectory. Discussed by Oliveira et al. (2014) was the notable difference between the amplitudes of the trajectory oscillation in their model (panel E in Figure 1) and their measurement (panel F). They additionally argued that this difference was correlated with the difference between their corresponding calculated and measured landing times, as tabulated in Table 1. On the other hand, Figure 1 suggests that the amplitude obtained in the current simulations, regardless of the formula used $x_{\mathrm{cp}}$, was significantly more consistent with the experimental data of Oliveira et al. (2014). When the $x_{\mathrm{cp}}$ formulas of Rayleigh (1876) (panel A) and Marchildon et al. (1964) (panel B) were used, the amplitudes of the trajectories were slightly larger than those observed in the experiment and accordingly, the calculated landing times were slightly smaller than the measured landing time. When the formula of Rosendahl (2000) (panel C) was used, the calculated amplitude seemed to be more consistent with the amplitude in the experiment. However, the calculated landing time was greater than the measured landing time by a larger amount. When the formula of Yin et al. (2003) (panel D) was used in the calculations, the resulting amplitude was larger than both the measured amplitude and the amplitude measured by other formals. However, the landing time was closer to the measured landing time.

\subsection{Flow Model Validation}

The flow model used here was first validated against the previous experimental and modeling data obtained in a wind tunnel for a flow over a cubic block (Lim et al., 2009). The test section of the wind tunnel had dimensions of $4.5 \times 0.9 \times 0.6 \mathrm{~m}$ (length, width and height, respectively) with a cube of height of $0.08 \mathrm{~m}$ situated $2.36 \mathrm{~m}$ from the inlet of the tunnel. Figure 2 displays the computational domain $0.8 \times 0.4 \times 0.4 \mathrm{~m}$ with a gird resolution of $320 \times 160 \times 160$ and the cube with height $0.08 \mathrm{~m}$. The computational configuration and resolution here are consistent with the simulation of Lim et al. (2009). A power law profile was set as the inlet boundary condition with a power law exponent of 0.18. Consistent with the simulation of Lim et al. (2009), a Reynolds number of $\operatorname{Re}_{h}=U_{h} h / v=20,000$, where $h$ is a reference length identical to the cube height and $U_{h}=4.5 \mathrm{~m} / \mathrm{s}$ is the reference velocity at the inlet at the vertical location $z=h$. It is noted that Lim et al. (2009) reported that they conducted their experiments for Reynolds numbers in the range between 18,600 and 73, 100 but did not find the mean and variance of measured velocities to significantly change at this range of Reynolds numbers. The lateral and top boundaries were set to be free slip and the outflow boundary condition was set to be open. At the inlet, turbulence with the intensity of $5 \%$ was introduced. 
TABLE 1 | Landing time of a cylindrical firebrand released in a still air in the previous experiment and simulation (Oliveira et al., 2014), and present simulations using different formula for the center of pressure $x_{\mathrm{cp}}$ (Rayleigh, 1876; Marchildon et al., 1964; Rosendahl, 2000; Yin et al., 2003).

\begin{tabular}{|c|c|c|c|}
\hline & Landing time (s) & Formula of $x_{c p} / I$ & References \\
\hline$A$ & 1.5312 (present) & $0.75 \sin \alpha /(4+\pi \cos \alpha)$ & Rayleigh (1876) \\
\hline$B$ & 1.5246 (present) & $(90-\alpha) / 480$ & Marchildon et al. (1964) \\
\hline C & 1.9397 (present) & $0.25\left(1-\sin ^{3} \alpha\right)$ & Rosendahl (2000) \\
\hline $\mathrm{D}$ & 1.6564 (present) & $0.125 \cos ^{3} \alpha$ & Yin et al. (2003) \\
\hline$E$ & 2.06 (previous) & $(90-\alpha) / 480$ & Oliveira et al. (2014) (simulation) \\
\hline $\mathrm{F}$ & $1.70 \pm 0.05$ (previous) & - & Oliveira et al. (2014) (experiment) \\
\hline
\end{tabular}

A

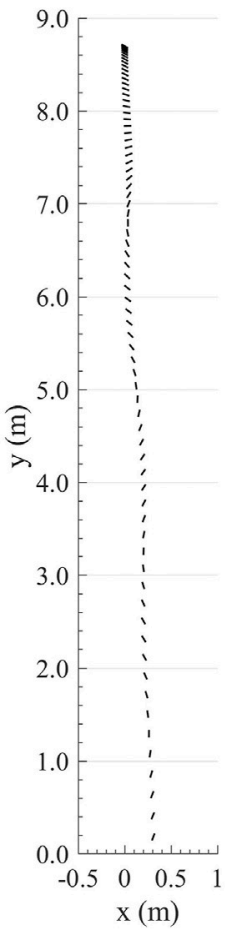

B

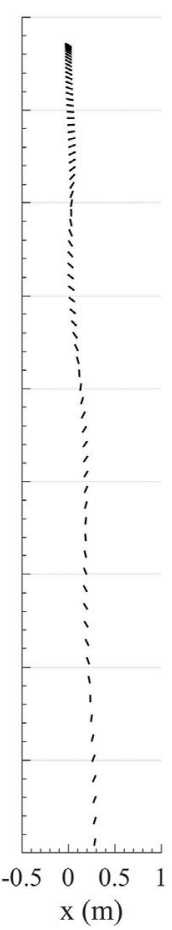

C

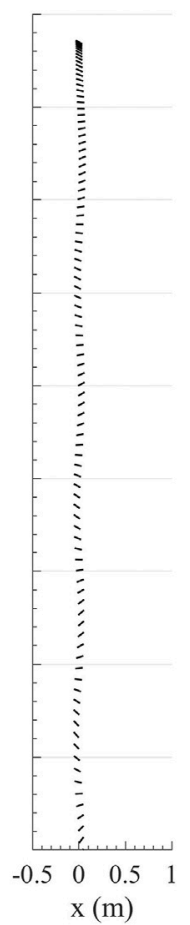

D

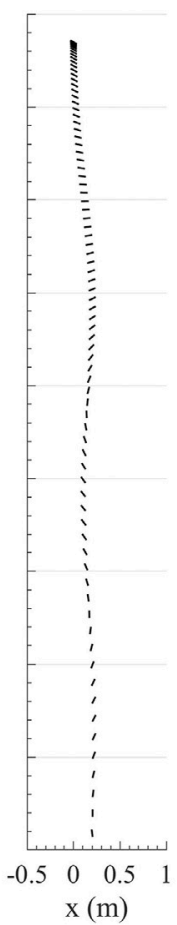

E

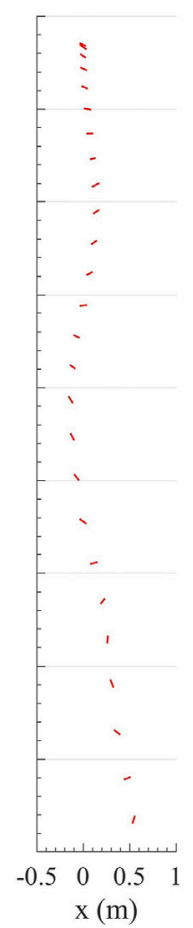

F

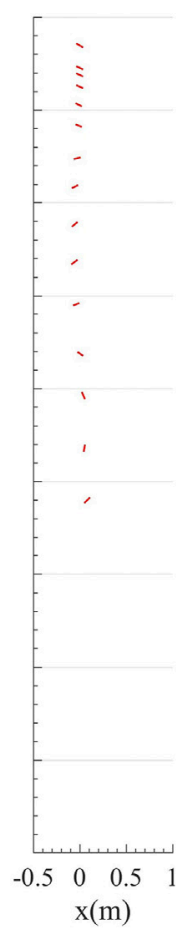

FIGURE 1 | Trajectory of a cylindrical particle released in still air condition in the present simulations using center of pressure formulation of (A) Rayleigh (1876); (B) Marchildon et al. (1964); (C) Rosendahl (2000); (D) Yin et al. (2003); (E) Oliveira et al. (2014); and (F) the experiment of Oliveira et al. (2014).

Flow turbulence was dealt with by LES with the Deardoff SGS (Deardorff, 1980) and near-wall models, as discussed in Section 2.2. However, the simulations were repeated with other SGS models including constant Smagorinsky (Smagorinsky, 1963), dynamic Smagorinsky (Germano et al., 1991; Moin et al., 1991), Vreman (Vreman, 2004) and RNG (Yakhot et al., 1989) available in FDS. It was determined that the results were negligibly sensitive to the SGS models. Hence, only the results of the Deardoff model are presented here.

Figure 3 shows the mean velocity streamlines at a slice $y=0$ and $z=0.5 h$ obtained from present simulations. This figure shows the key flow structures around the cube, viz. the center of the horseshoe vortex, the flow separation and reattachment on the top and lateral faces, flow reattachment on the leeward side of the cube, the two counter rotating re-circulation region and the stagnation point of the windward face of the cube. Table 2 compares the locations of these points of interest obtained in the current study with those obtained in the simulation of Lim et al. (2009). The center of the horseshoe vortex obtained here is a little further away from the windward face of the cube when compared to the previous simulation (Lim et al., 2009). On the other hand, the locations of the stagnation point on the windward face of the cube, the reattachment length on the top face of the cube and the reattachment length on the leeward side of the cube obtained here closely match those in the simulation of Lim et al. (2009), as seen in Table 2.

Figure 4 shows the pressure coefficient $C_{\mathrm{p}}$ on the axial (i.e. $y / h=0$ ) and transverse (i.e. $x / h=0.5$ ) center-lines on the faces of the block as indicated in Figure 2 . As could be seen Figure 4, the pressure coefficient calculated here for the top 

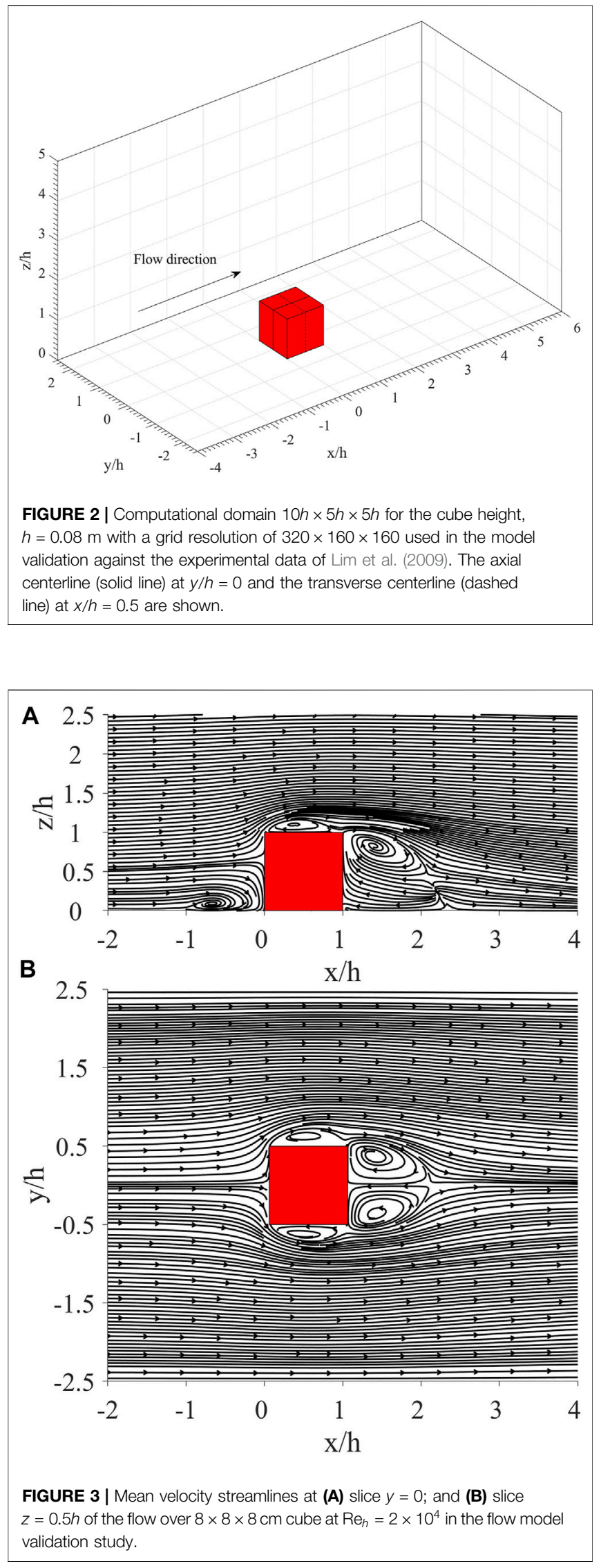

TABLE 2 | The locations of the center of the horseshoe vortex (HSV $\left(x_{H V C}, y_{H V C}\right)$ the stagnation point on the windward face $y_{\text {stag }}$; the flow reattachment point on the top face $x_{\text {top }}$ and the flow reattachment point on the leeward side of the structure $x_{\text {lee }}$ in the previous (Lim et al., 2009) and current simulations in the flow model validation study.

\begin{tabular}{lcccc} 
& $\left(\mathbf{x}_{\mathbf{H v c}}, \mathbf{y}_{\mathbf{H v c}}\right)$ & $\mathbf{y}_{\text {stag }}$ & $\mathbf{x}_{\text {top }}$ & $\mathbf{x}_{\text {lee }}$ \\
\hline Simulation of Lim et al. (2009) & $(-0.50,0.10 h)$ & $0.73 h$ & $0.75 h$ & $1.56 h$ \\
Present simulation & $(-0.74,0.08 h)$ & $0.66 h$ & $0.83 h$ & $1.51 h$ \\
\hline
\end{tabular}

face of the cube compares very well against the experimental and simulation data of Lim et al. (2009). The agreement between the current simulation and the previous works for this coefficient is reasonable for the rest of the faces. The experimental data of Richards et al. (2001) is also shown here for a comparison albeit they were obtained for a different Reynolds number of $4.1 \times 10^{6}$. The profile in Figure 4A shows the largest positive pressure on the windward face of the cube closer to the leading edge which is a result of the cube blocking the flow. On the top face, the largest negative pressure right after the leading edge is associated with the flow separation at the leading edge which is followed pressure recovery corresponding to the flow reattachment.

In Figure 5, the mean streamwise and vertical velocities are plotted vs. $z$ on the axial centerline of the top face of the block at various $x$ 's. The agreement between the current simulation and the previous experiment and simulation (Lim et al., 2009) is very good. The change of the velocity profile in the $x$ direction is attributed to the flow separation on the top face.

Figure 6 shows the profiles of the root mean square (rms) of the streamwise and vertical velocities as well as the Reynolds shear stress at various $x$ 's on the axial center-line of the top face of the block. As could be seen in Figures 6A,B, the current simulation substantially over-predicts the rms values obtained in the previous experiments and the simulation (Lim et al., 2009). On the other hand, the Reynolds shear stress in the simulation is in reasonably good agreement with the previous experimental and simulation data.

\subsection{Firebrand Deposition in the Flow Over a Single Structure}

Figure 7 shows the computational configuration used in the simulation of firebrand deposition in a flow over a single cubic structure. The length, width and height of the structure are indicated by $L, W$ and $H$, which are its dimensions in the $x, y$ and $z$ directions, respectively. Simulations were carried out for structures with various lengths, widths and heights. The domain size is $75 \times 36 \times 36 \mathrm{~m}$ in the $x, y$ and $z$ directions, respectively. The domain is divided into two sub-domains with a finer gird $(0.15 \times 0.15 \times 0.15 \mathrm{~m})$ between heights $0-12 \mathrm{~m}$ and a coarse grid $(0.3 \times 0.3 \times 0.3 \mathrm{~m})$ between heights $12-36 \mathrm{~m}$. The inlet flow velocity was specified by a power law with an exponent of 0.18 with a velocity of $6 \mathrm{~m} / \mathrm{s}$ at a reference height $h=3 \mathrm{~m}$ which resulted in $\operatorname{Re}_{h}=1 \times 10^{6}$. The turbulent intensity at the inlet was set to $20 \%$. This inlet boundary condition is an approximate 

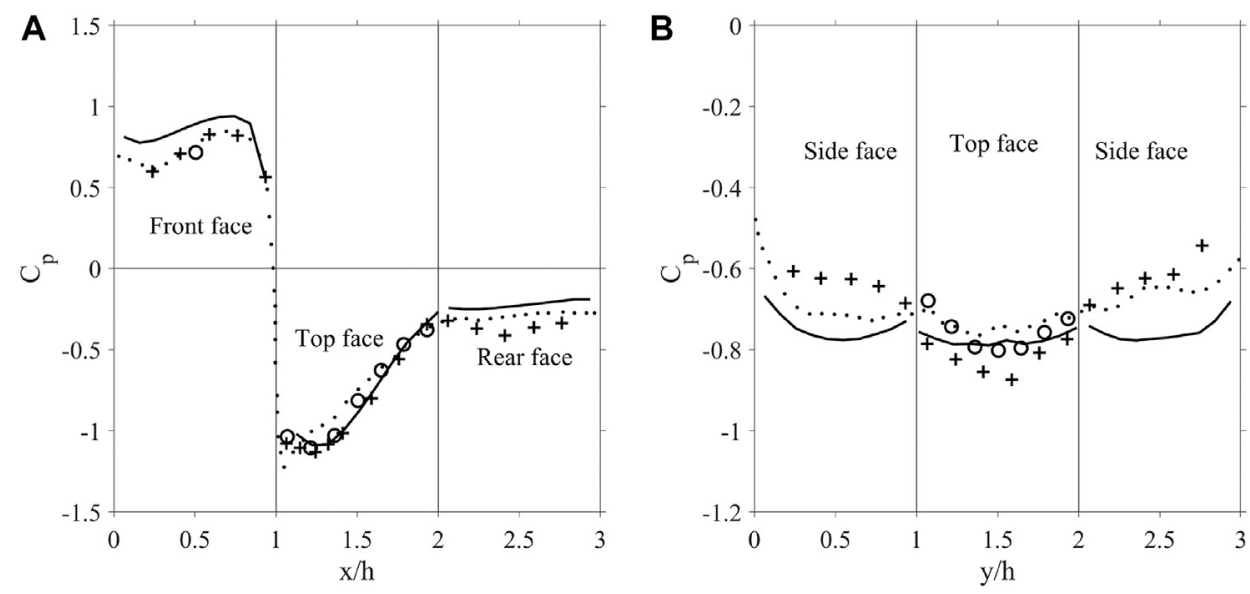

FIGURE 4|Pressure coefficient on the surface of the cube in the flow validation study; $\mathbf{( A )}$ the axial centerline where $y / h=0$; and $(\mathbf{B})$ the transverse centreline where $x / h=0.5$ in the experiments of Lim et al. (2009) (०) and Richards et al. (2001) (+), the simulations of Lim et al. (2009) (dotted line) and the present computational study (solid line).
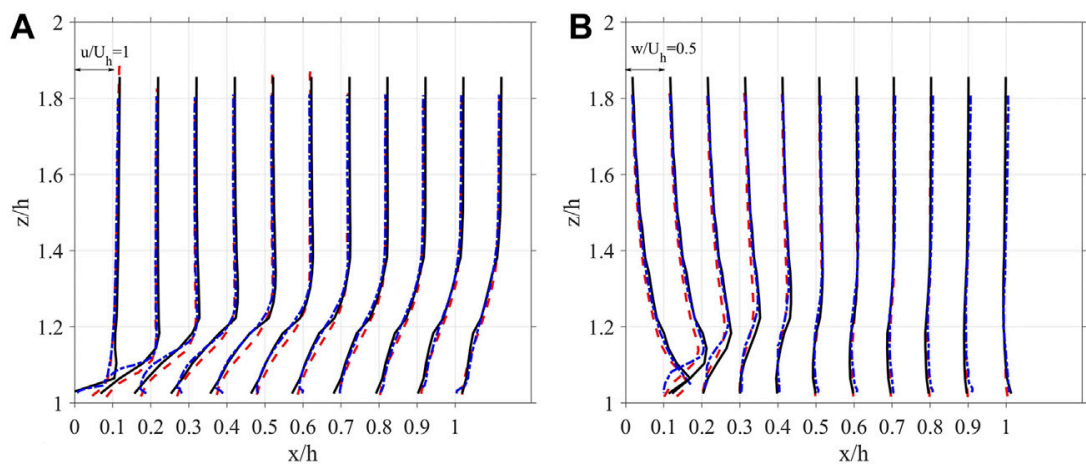

FIGURE 5 |Profiles of (A) the streamwise mean velocity; and (B) the vertical mean velocity in the flow model validation study; the experiment (blue dashed-dotted line), and simulation (red dashed line) of Lim et al. (2009) and the present simulation (solid line).

representation of a neutrally stable ASL. The modeling approaches such as SGS turbulent closure model and the nearwall models are the same described in Section 3.2. The dimension and velocity scales the structures are selected here to be relevant to WUI.

The firebrands were released every second from positions with coordinates randomly selected with a uniform distribution from a horizontal plane passing $z=35 \mathrm{~m}$, as shown in Figure 7, after the flow reached a statistically stationary state. At the release points, firebrands had a zero velocity with the orientation of $60^{\circ}$ with respect to the vertical axis and the initial firebrand temperature $T_{\mathrm{p}}=773 \mathrm{~K}$. The initial firebrand mass density was $570 \mathrm{~kg} / \mathrm{m}^{3}$, and the firebrand diameter and length of $3 \mathrm{~mm}$ and $40 \mathrm{~mm}$, respectively (Manzello et al., 2007). Considering the flow and firebrand release conditions, the simulations here will be relevant to long range spotting. The random initial distribution of firebrands is to account for the uncertainty of the firebrand release point.
To quantify the spatial distribution of the firebrands deposited on the ground and the top face of the block, a criterion proposed by Anand et al. (2018) with the following function, was used:

$$
\widehat{f}(x, y)=\frac{1}{n B^{2}} \sum_{i=1}^{n} \kappa\left(\frac{x-x_{i}}{B}, \frac{y-y_{i}}{B}\right)
$$

where $n$ is the total number of the deposited firebrands, and $\kappa(\cdot, \cdot)$ is the kernel function with $\widehat{f}$ satisfying the normalization condition $\iint \hat{f} d x d y=1$. Here, $B$ is the bandwidth, which set to $0.25 \mathrm{~m}$ in this study, and $x_{i}$ and $y_{i}$ are the landing coordinates of the firebrand number $i$. In the simulation, $n \sim 3.8 \times 10^{6}$ firebrands were deposited. The reason for release of many firebrands is to generate enough samples for the statistical description of the deposition location of firebrands. A Gaussian function was selected as the kernel function MathWorks (2019a) here. It is noted that $\hat{f}(x, y)$ 

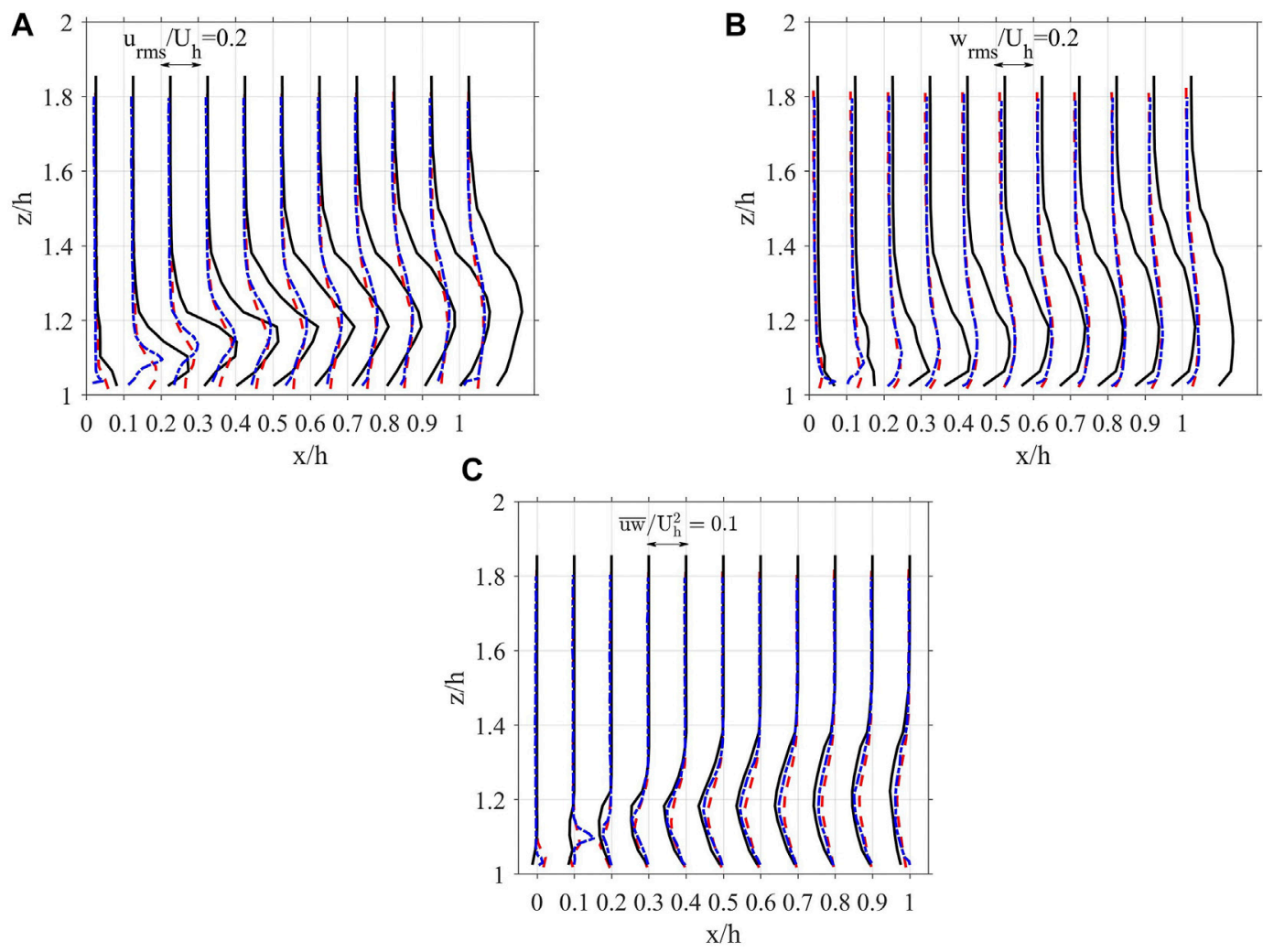

FIGURE 6 |Profiles of (A) the streamwise velocity rms; (B) the vertical velocity rms; and (C) Reynolds shear stress $\overline{\text { UW }}$ in flow model validation study; the experiment (blue dashed-dotted line) and simulation (red dashed line) of Lim et al. (2009), and the present simulation (solid line).

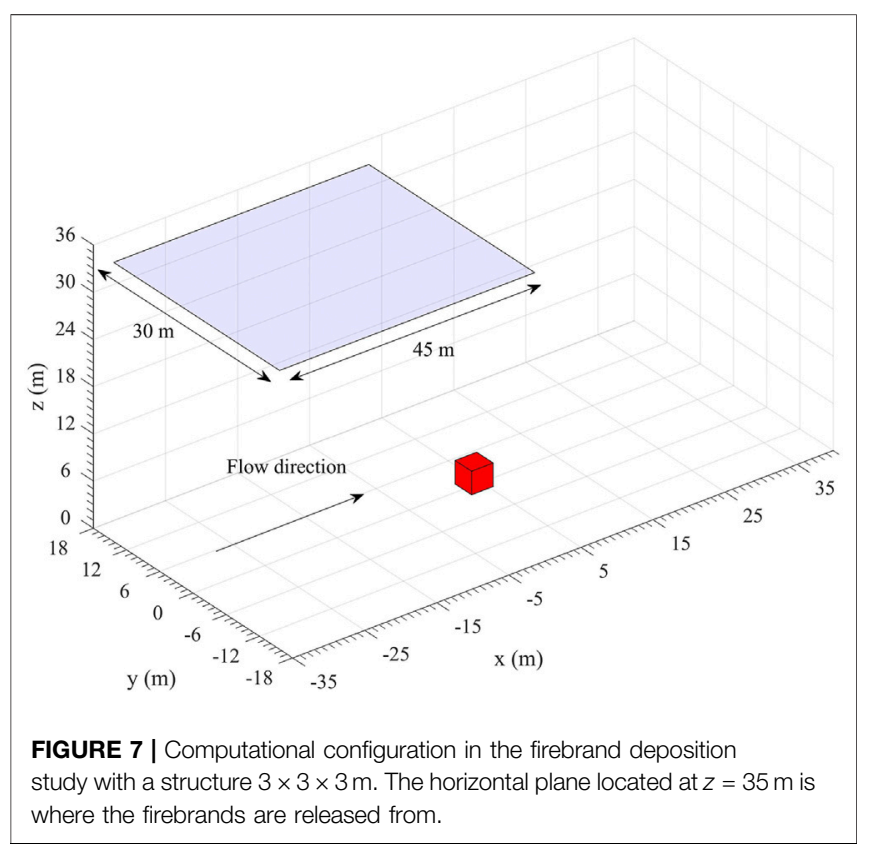

defined in Eq. 27 indicates the normalized number density (NND) of deposited firebrands, where the number density is defined as the number of firebrands deposited per unit area.
Figure 8 shows the mean velocity streamlines superimposed on the contour plots of mean velocity magnitude on the slice $y=0$ for varying structure sizes (panels $\mathrm{B}-\mathrm{H}$ ) and no structure (panel A). The streamline features here, when there is a structure, overall resemble the ones seen in Figure 3A, which is for a low Reynolds number. However, the details of these features are different for various displayed cases. In the group of structures (panels C, E, F) with fixed lengths and heights but varying widths, the horseshoe vortex and the length of the wake on the leeward side of the structure increases in size with the increase of the width. It can also be seen that the flow accelerates above the leading edge of the structure. This acceleration in the flow is more prominent for a group of structures (panels B,C,D) with fixed lengths and widths but varying heights, as the height of the structure increases. The length of the wake on the leeward side of the structure decreases slightly as the length of the structure increases as seen in the group of structures (panels $\mathrm{C}, \mathrm{G}, \mathrm{H}$ ).

Figure 9 shows a top view of the contour plots of NND of the deposited firebrands for cases displayed in Figure 8. As seen in this figure, there is a region of very low NND on the leeward side in panels with structures. Examining the scattered deposited particle data revealed that no firebrands were deposited on this region. This region is hereby referred to as the safe zone. The safe zone is approximately shaped like a rectangle with a 

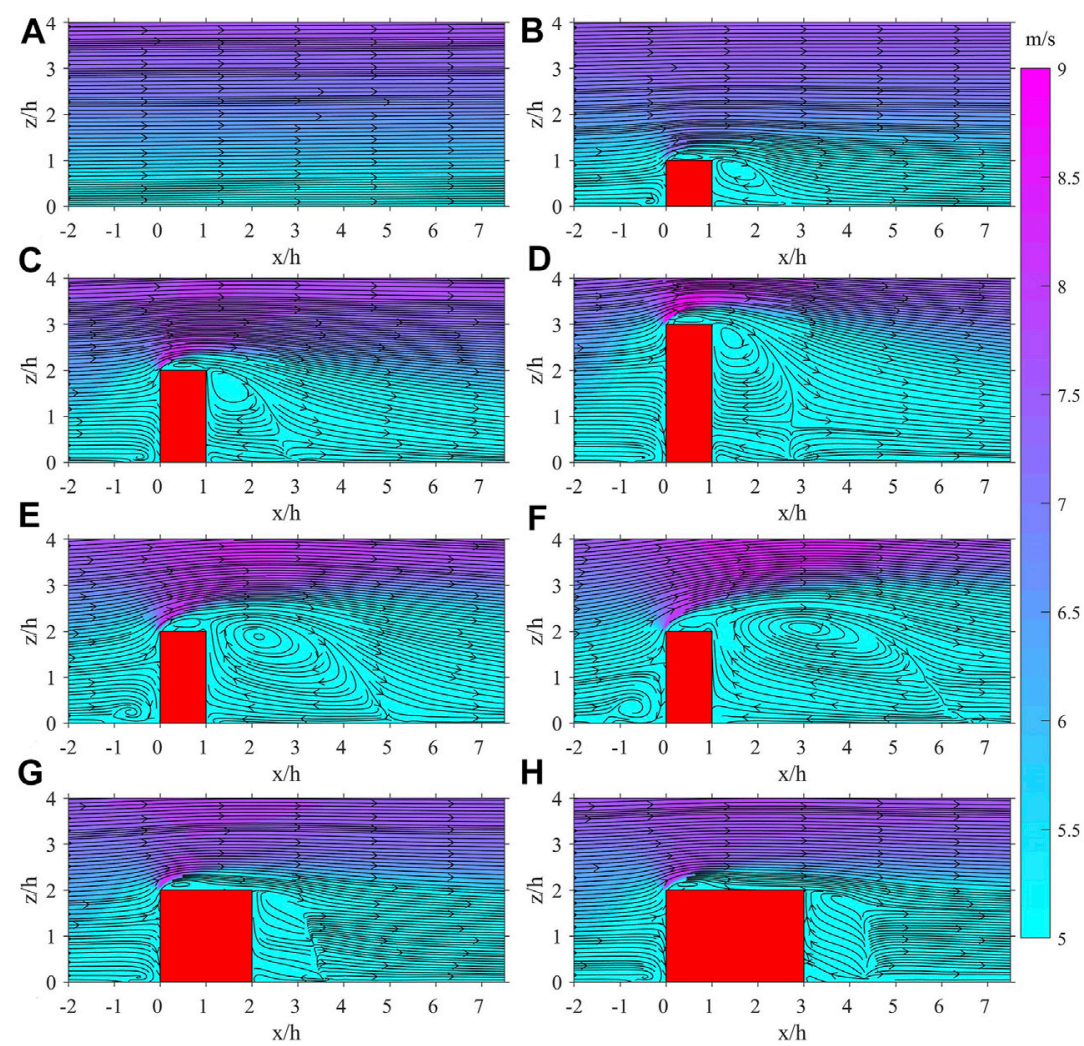

FIGURE 8|Mean velocity streamlines superimposed on the contour plots of mean velocity magnitude at slice $y=0$ (A) with no structure; and with structure with (B) $L=W=H=3 \mathrm{~m} ;$ (C) $L=W=3 \mathrm{~m}, H=6 \mathrm{~m} ;$ (D) $L=W=3 \mathrm{~m}, H=9 \mathrm{~m} ; \mathbf{( E )} L=3 \mathrm{~m}, W=H=6 \mathrm{~m} ;(\mathbf{F}) L=3 \mathrm{~m}, W=9 \mathrm{~m}, H=6 \mathrm{~m} ;(\mathbf{G}) L=H=6 \mathrm{~m}, W=3 \mathrm{~m} ;$ (H) $L=9 \mathrm{~m}$, $W=3 \mathrm{~m}, H=6 \mathrm{~m}$.

length $l_{r}$ and a width $w_{r}$ (in the spanwise direction), which is almost identical to the width of the structure $W$. The length $l_{r}$ is calculated as the distance from the leeward face of the structure to where the NND is $3.85 \times 10^{-4}$. As seen in Figure 9, the safe zone length is larger for the structures with larger heights. Figure 10 displays $l_{r}$ vs. $H$ and indicates that for every $3 \mathrm{~m}$ increase of the structure height, the safe zone length increases roughly by one meter. The change in width $W$ or length $L$ of the structure barely affected the length of the safe zone. The simulation of the structure size $L=W=H=3 \mathrm{~m}$ was repeated with a grid size twice larger in each direction and it was found that $l_{r}$ decreased less than $6 \%$.

Figures 11A-C shows the NND of deposited firebrands vs. $x$ at $y=0$ and Figures 11E,F plots it against $y$ at $x=0$ for various structure sizes and the case with no structure. Seen in Figures 11A-C, are distinct troughs in cases with a structure, which correspond to the safe zones. It is also seen in these panels that NND overall decreases from the leading to the trailing edge on top of the structures. This feature is associated with the flow separation that occurs on top faces of the block, which is visible in Figure 8. It is seen in Figures 8G, H, which are for the blocks with longer lengths, this separated flow reattaches. It is believed that this reattachment gives rise to the local peaks of NND on the top face of the structure which are more pronounced for $L=6$ and $9 \mathrm{~m}$ in Figure 11C. This could be a result of some firebrands gaining momentum from the accelerated flow above the leading edge of the structure (Figure 8) and depositing closer to its trailing edge. The curves of the cases with structures in Figures 11D-F show that the NND on top faces overall has smaller values compared to the neighboring areas on the ground. Figures 11A,D shows that an increase in the height of the structure results in a slightly higher NND on the top face of the structure.

Table 3 shows the number of firebrands deposited and their temperatures on the top, front and lateral faces of the structure. In none of the cases, a firebrand was deposited on the back face of the structure. This table shows that in the cases with varying height but the same width and length, the number of firebrands deposited on the top face and their average temperature increase with an increasing height. The reason for this average temperature increase is that overall as firebrands descend, their temperatures drop. Figure 12 shows the exact location and temperature of each deposited firebrand on all faces of one of the considered structures but the leeward face. As noted earlier, the leeward face did not receive any firebrands in any of the cases. As evident in this figure, the temperature of the 

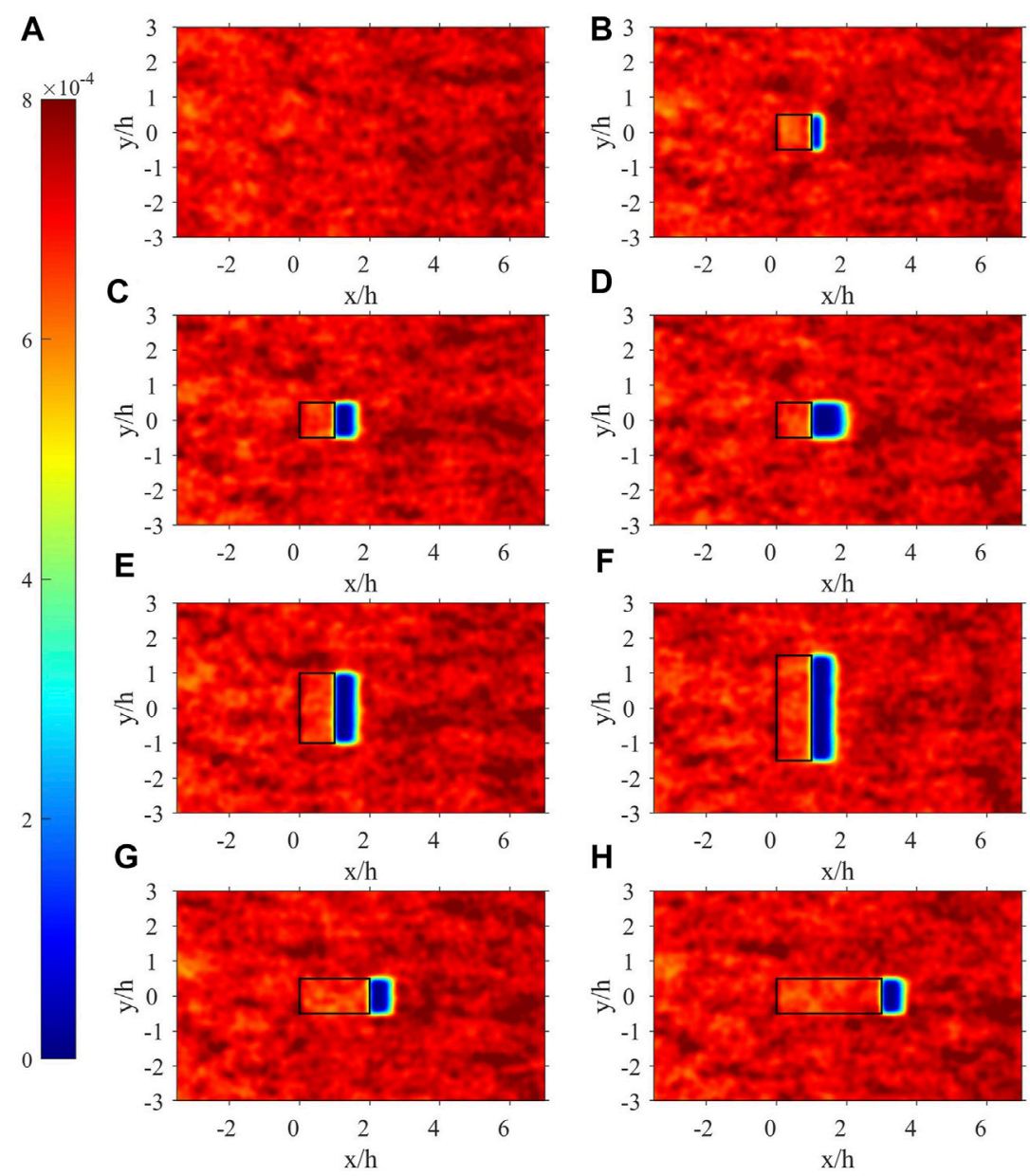

FIGURE 9 | Contour plots of normalized number density of the deposited firebrands on the ground (A) with no structure; top face and the ground around single structures with (B) $L=W=H=3 \mathrm{~m} ;$ (C) $L=W=3 \mathrm{~m}, H=6 \mathrm{~m} ;$ (D) $L=W=3 \mathrm{~m}, H=9 \mathrm{~m} ;$ (E) $L=3 \mathrm{~m}, W=H=6 \mathrm{~m} ;(\mathbf{F}) L=3 \mathrm{~m}, W=9 \mathrm{~m}, H=6 \mathrm{~m} ;(\mathbf{G}) L=H=6 \mathrm{~m}$, $W=3 \mathrm{~m} ; \mathbf{( H )} L=9 \mathrm{~m}, W=3 \mathrm{~m}, H=6 \mathrm{~m}$.

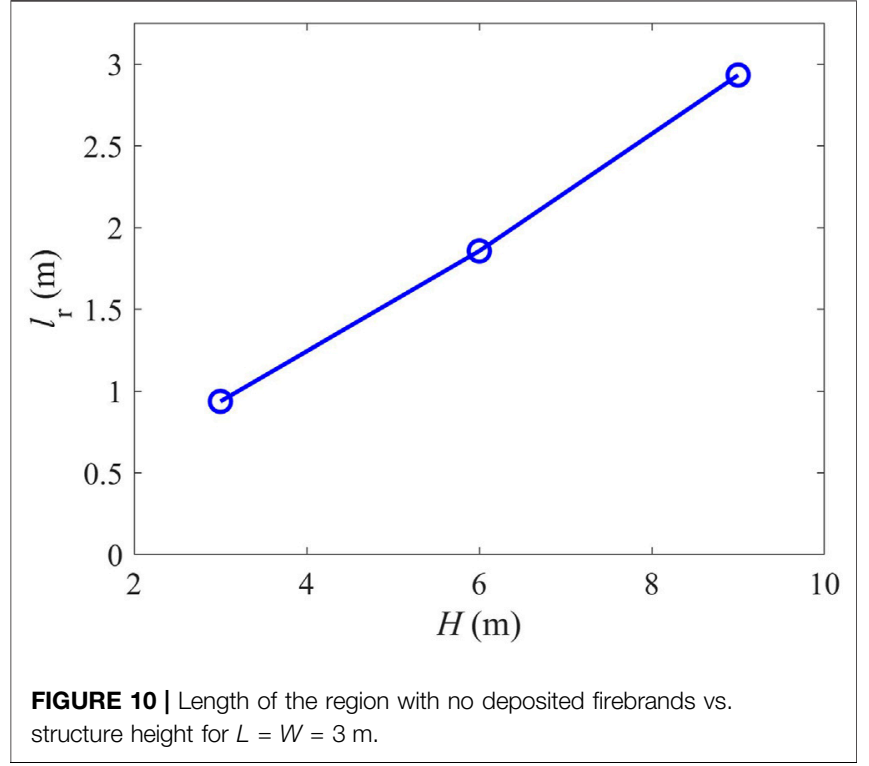

firebrands deposited on the windward face decrease with the decrease of $z$. A triangular like region with no firebrands on either lateral face of the block is noticeable.

\section{SUMMARY AND CONCLUSION}

A model was developed for simulation of cylindrical firebrand motion and burning in the FDS computational framework. The model was validated against the previous experimental and computational data (Oliveira et al., 2014) for a firebrand falling in a no-wind condition. The current model showed better agreement with the experimental data than the previous computational model. In addition, the previous experimental and CFD data (Lim et al., 2009) for a flow over a mounted $0.08 \mathrm{~m}$ height cube in a wind tunnel was used to validate FDS for simulation of flows over obstacles. The pressure coefficients in the simulation was in relatively good agreement with the experimental data. The mean velocity profiles in the streamwise 

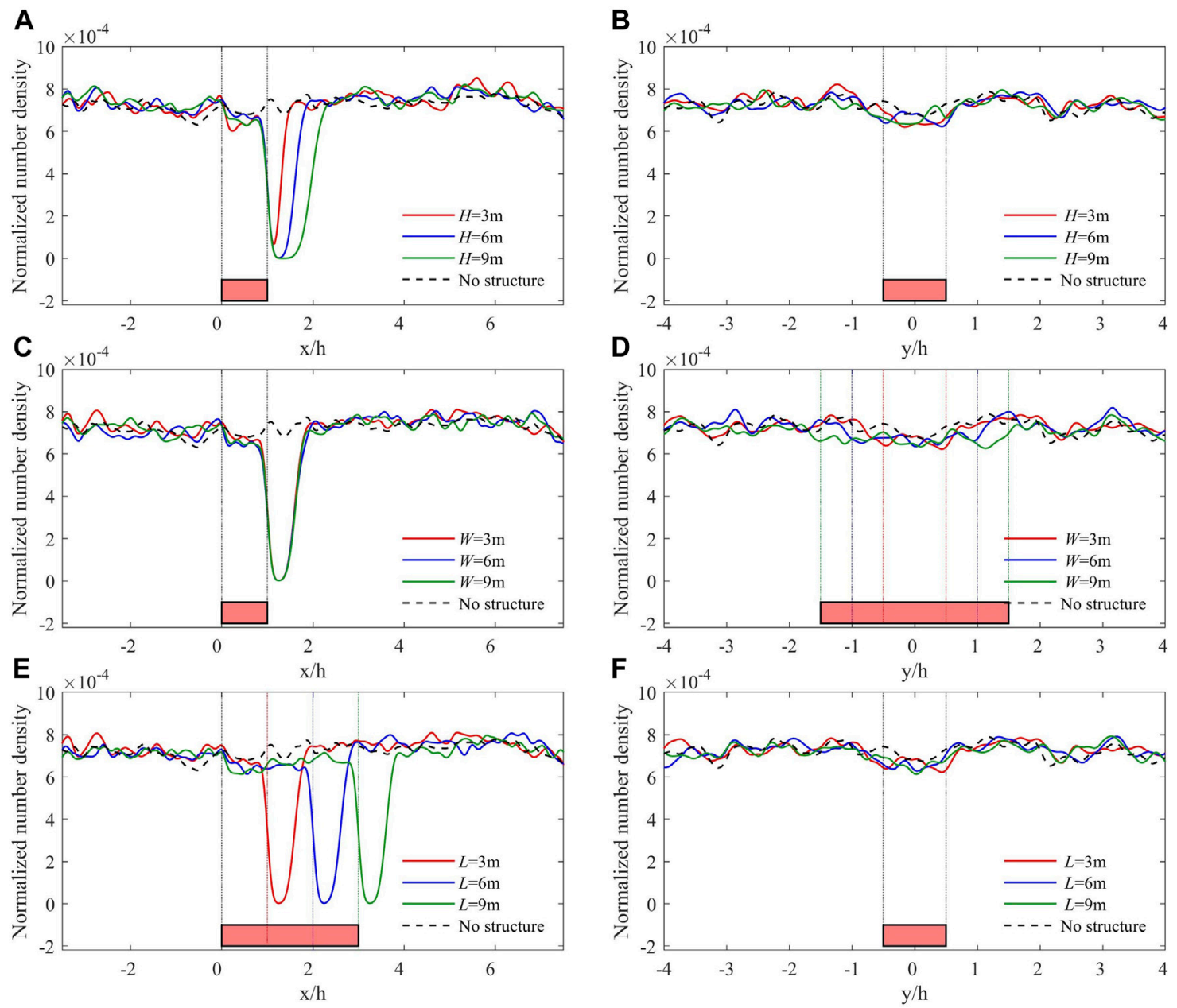

FIGURE 11 | Normalized number density of deposited firebrands vs. $x$ at $y=0$ on the left panels and vs. $y$ at $x=0$ on the right panels for $(\mathbf{A}, \mathbf{D}) L=W=3$ m; (B,E) $H=6 \mathrm{~m}$ and $L=3 \mathrm{~m}$; and $\mathbf{( C , F ) ~} H=6 \mathrm{~m}$ and $W=3 \mathrm{~m}$.

TABLE 3 | Number and average temperature $(K)$ of firebrands deposited on the top, front and lateral faces of the structure.

\begin{tabular}{|c|c|c|c|c|c|c|}
\hline \multirow{2}{*}{$\frac{\text { Cases }}{L \times W \times H}$} & \multicolumn{2}{|c|}{ Top face } & \multicolumn{2}{|c|}{ Front face } & \multicolumn{2}{|c|}{ Lateral faces } \\
\hline & No & Avg. temp & No & Avg. temp & No & Avg. temp \\
\hline $3 m \times 3 m \times 3 m$ & 22,949 & 424.92 & 6,820 & 418.77 & 244 & 419.17 \\
\hline $3 m \times 3 m \times 6 m$ & 23,428 & 436.24 & 14,112 & 424.06 & 428 & 424.22 \\
\hline $3 m \times 3 m \times 9 m$ & 23,670 & 448.82 & 21,959 & 430.33 & 494 & 435.97 \\
\hline $3 \mathrm{~m} \times 6 \mathrm{~m} \times 6 \mathrm{~m}$ & 46,927 & 435.49 & 28,425 & 423.69 & 351 & 426.71 \\
\hline $3 \mathrm{~m} \times 9 \mathrm{~m} \times 6 \mathrm{~m}$ & 70,412 & 435.06 & 43,367 & 423.34 & 443 & 424.94 \\
\hline $6 m \times 3 m \times 6 m$ & 46,737 & 436.19 & 14,154 & 424.15 & 1,006 & 425.17 \\
\hline $9 \mathrm{~m} \times 3 \mathrm{~m} \times 6 \mathrm{~m}$ & 71,267 & 436.17 & 14,192 & 424.09 & 1,516 & 424.73 \\
\hline
\end{tabular}

and vertical directions as well as the Reynolds shear stress in the simulation closely matched the experimental data. On the other hand, the simulation substantially over-predicted the measured rms of the velocities in the streamwise and vertical directions. The developed firebrand model then used with FDS to simulate the deposition of firebrands carried by a flow over a rectangular cubic structure, as a representative of a single structure in an open domain. The Reynolds number in the deposition study was an order of magnitude larger than that in the validation study. A parametric study was conducted where heights, widths and lengths were varied from 3 to $9 \mathrm{~m}$. It revealed an area on the leeward side of the structure on the ground where no firebrands 


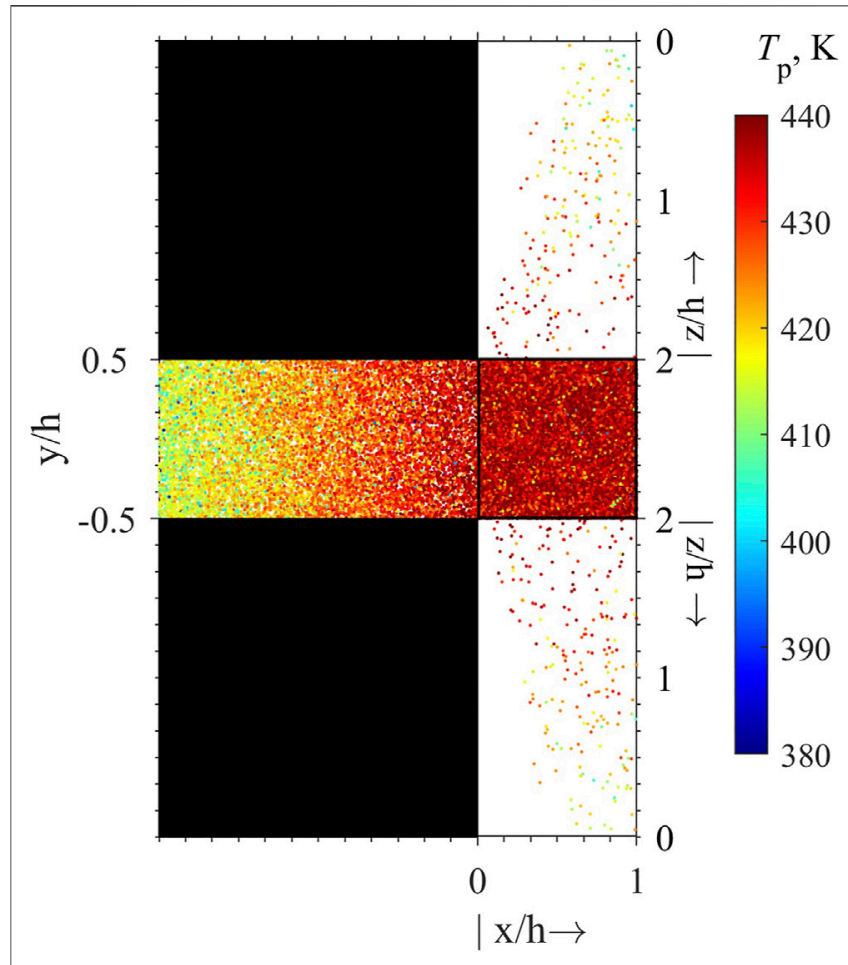

FIGURE 12 | Location and temperature of the firebrands deposited on the faces of the structure with length and width of $3 \mathrm{~m}$ and height of $6 \mathrm{~m}$. Dots indicate the positions of the deposited firebrands on the block faces. The leeward face is not shown since no firebrands are deposited on it. The rectangles with the smallest number of dots are the lateral faces. The square between these two faces is the top face. The rectangle on the left of the top face is the windward face.

were deposited. This area was refereed to as the safe zone. The width of the zone was the same as the width of the structure (the dimension of the structure in the spanwise direction). The length of this zone in the streamwise direction was proportional to the height of the structure. No firebrand was deposited on the leeward face of the structure regardless of the size of the structure. The NND on the top face of the structure increases slightly with its height. For structures with longer lengths, the NND dropped near the leading edge and rose back again toward the trailing edge of the structure. This effect was attributed to the flow accelerating above the leading edge of the structure thus imparting extra momentum onto the firebrands and carrying them farther away.

Shapes of the structures considered here were simple but fundamental. Understanding the problem in fundamental

\section{REFERENCES}

Anand, C. (2018). “Computational Investigations of Ignition Characteristics of Live Fuels and Deposition of Firebrands in a Turbulent Boundary Layer,". Ph.D. thesis (The University of Alabama in Huntsville).

Anand, C., Shotorban, B., and Mahalingam, S. (2018). Dispersion and Deposition of Firebrands in a Turbulent Boundary Layer. Int. setups seems an essential first step but considerations should be given to shapes representing more realistic structures. Realistic structures can significantly change from one to another in shape while involving additional geometric parameters, which can hinder the interpretation of the results. It is noted that the dimensions chosen for the structures here ranged from 3 to $9 \mathrm{~m}$ which are relevant to the overall dimensions of realistic small structures, e.g., houses. Future work should include sensitivity studies of the wind speed and direction. It should also include heat flux transferred from the deposited firebrands because of its consequence on ignition of the recipient fuel. Calculations of this flux require additional models to represent this phenomenon.

\section{DATA AVAILABILITY STATEMENT}

The data that support the findings of this study are available from the corresponding author upon reasonable request.

\section{AUTHOR CONTRIBUTIONS}

AM made changes to the code, ran the simulation and post processed the acquired data for this study under the supervision of BS. Both authors contributed to the development of the manuscript.

\section{FUNDING}

This work was performed under the following financial assistance award 70NANB17H281 from United States Department of Commerce, National Institute of Standards and Technology.

\section{ACKNOWLEDGMENTS}

The authors acknowledge the work by Chandanda Anand on integration of the firebrand model with the FDS version used in this study. The authors acknowledge the help received from Randall J. McDermott of NIST for the flow model validation study. High performance computing resources and technical support from the Alabama Supercomputer Authority are appreciated.

J. Multiphase Flow 109, 98-113. doi:10.1016/j.ijmultiphaseflow.2018. 07.012

Deardorff, J. W. (1980). Stratocumulus-capped Mixed Layers Derived from a Three-Dimensional Model. Boundary-layer Meteorol. 18, 495-527. doi:10. 1007/bf00119502

Germano, M., Piomelli, U., Moin, P., and Cabot, W. H. (1991). A Dynamic Subgrid-scale Eddy Viscosity Model. Phys. Fluids A: Fluid Dyn. 3, 1760-1765. doi:10.1063/1.857955 
Hoerner, S. F. (1965). Fluid-dynamic Drag. Hoerner Fluid Dyn.

Kelbaliyev, G. I. (2011). Drag Coefficients of Variously Shaped Solid Particles, Drops, and Bubbles. Theor. Found. Chem. Eng. 45, 248-266. doi:10.1134/ s0040579511020084

Lee, S., and Bienkiewicz, B. (1997). Large-eddy Simulation of Wind Effects on bluff Bodies Using the Finite Element Method. J. wind Eng. Ind. aerodynamics 67-68, 601-609. doi:10.1016/s0167-6105(97)00103-7

Lim, H. C., Thomas, T. G., and Castro, I. P. (2009). Flow Around a Cube in a Turbulent Boundary Layer: LES and experiment. J. Wind Eng. Ind. Aerodynamics 97, 96-109. doi:10.1016/j.jweia.2009.01.001

Manzello, S. (2014). Enabling the Investigation of Structure Vulnerabilities to Wind- Driven Firebrand Showers in Wildland-Urban Interface (WUI) Fires. Fire Saf. Sci. 11, 83-96. doi:10.3801/iafss.fss.11-83

Manzello, S. L., Maranghides, A., and Mell, W. E. (2007). Firebrand Generation from Burning Vegetation. Int. J. Wildland Fire 16, 458-462. doi:10.1071/wf06079

Manzello, S. L., Shields, J. R., Cleary, T. G., Maranghides, A., Mell, W. E., Yang, J. C., et al. (2008). On the Development and Characterization of a Firebrand Generator. Fire Saf. J. 43, 258-268. doi:10.1016/j.firesaf.2007. 10.001

Marchildon, E. K., Clamen, A., and Gauvin, W. H. (1964). Drag and Oscillatory Motion of Freely Falling Cylindrical Particles. Can. J. Chem. Eng. 42, 178-182. doi:10.1002/cjce.5450420410

MathWorks (2019a). Multivariant Kernel Smoothing Density.

McGrattan, K., Hostikka, S., Floyd, J., McDermott, R., and Vanella, M. (2018). Fire Dynamics Simulator Technical Reference Guide Volume 1: Mathematical Model. NIST Special Publication. Sixth Edition. U.S. Department of Commerce, National Institute of Standards and Technology, 1018-1026.

Mell, W., Maranghides, A., McDermott, R., and Manzello, S. L. (2009). Numerical Simulation and Experiments of Burning douglas Fir Trees. Combustion and Flame 156, 2023-2041. doi:10.1016/j.combustflame.2009.06.015

Moin, P., Squires, K., Cabot, W., and Lee, S. (1991). A Dynamic Subgrid-scale Model for Compressible Turbulence and Scalar Transport. Phys. Fluids A: Fluid Dyn. 3, 2746-2757. doi:10.1063/1.858164

Morvan, D., and Dupuy, J. L. (2004). Modeling the Propagation of a Wildfire through a Mediterranean Shrub Using a Multiphase Formulation. Combustion and flame 138, 199-210. doi:10.1016/j.combustflame.2004.05.001

Murakami, S., Mochida, A., and Hibi, K. (1987). Three-dimensional Numerical Simulation of Air Flow Around a Cubic Model by Means of Large Eddy Simulation. J. Wind Eng. Ind. Aerodynamics 25, 291-305. doi:10.1016/01676105(87)90023-7

Nicoud, F., and Ducros, F. (1999). Subgrid-scale Stress Modelling Based on the Square of the Velocity Gradient Tensor. Flow, turbulence and Combustion 62, 183-200. doi:10.1023/a:1009995426001

Oliveira, L. A., Lopes, A. G., Baliga, B. R., Almeida, M., and Viegas, D. X. (2014). Numerical Prediction of Size, Mass, Temperature and Trajectory of Cylindrical Wind-Driven Firebrands. Int. J. Wildland Fire 23, 698-708. doi:10.1071/wf13080

Rayleigh, L. (1876). LIII. On the Resistance of Fluids. Lond. Edinb. Dublin Phil. Mag. J. Sci. 2, 430-441. doi:10.1080/14786447608639132

Richards, P. J., Hoxey, R. P., Connell, B. D., and Lander, D. P. (2007). Wind-tunnel Modelling of the Silsoe Cube. J. Wind Eng. Ind. Aerodynamics 95, 1384-1399. doi:10.1016/j.jweia.2007.02.005
Richards, P. J., Hoxey, R. P., and Short, L. J. (2001). Wind Pressures on a $6 \mathrm{~m}$ Cube. J. Wind Eng. Ind. Aerodynamics 89, 1553-1564. doi:10.1016/s0167-6105(01) 00139-8

Rodi, W. (1998). Large-eddy Simulations of the Flow Past bluff Bodies: State-OfThe Art. JSME International Journal. Ser. B, Fluids Thermal Engineering 41, 361-374. doi:10.1299/jsmeb.41.361

Rosendahl, L. (2000). Using a Multi-Parameter Particle Shape Description to Predict the Motion of Non-spherical Particle Shapes in Swirling Flow. Appl. Math. Model. 24, 11-25. doi:10.1016/s0307-904x(99)00023-2

Sardoy, N., Consalvi, J. L., Kaiss, A., Fernandez-Pello, A. C., and Porterie, B. (2008). Numerical Study of Ground-Level Distribution of Firebrands Generated by Line Fires. Combustion and Flame 154, 478-488. doi:10.1016/j.combustflame.2008.05.006

Sardoy, N., Consalvi, J., Porterie, B., and Fernandezpello, A. (2007). Modeling Transport and Combustion of Firebrands from Burning Trees. Combustion and Flame 150, 151-169. doi:10.1016/j.combustflame.2007.04.008

Smagorinsky, J. (1963). General Circulation Experiments with the Primitive Equations. Mon. Wea. Rev. 91, 99-164. doi:10.1175/1520-0493(1963) 091<0099:gcewtp > 2.3.co;2

Song, J., Huang, X., Liu, N., Li, H., and Zhang, L. (2017). The Wind Effect on the Transport and Burning of Firebrands. Fire Technol. 53, 1555-1568. doi:10. 1007/s10694-017-0647-1

Tarifa, C. S., del Notario, P. P., and Moreno, F. G. (1967). "Transport and Combustion of Fire Brands,".

Tohidi, A., and Kaye, N. B. (2017a). Comprehensive Wind Tunnel Experiments of Lofting and Downwind Transport of Non-combusting Rod-like Model Firebrands during Firebrand Shower Scenarios. Fire Saf. J. 90, 95-111. doi:10.1016/j.firesaf.2017.04.032

Tohidi, A., and Kaye, N. B. (2017b). Stochastic Modeling of Firebrand Shower Scenarios. Fire Saf. J. 91, 91-102. doi:10.1016/j.firesaf.2017.04.039

Vreman, A. W. (2004). An Eddy-Viscosity Subgrid-Scale Model for Turbulent Shear Flow: Algebraic Theory and Applications. Phys. Fluids 16, 3670-3681. doi:10.1063/1.1785131

Werner, H., and Wengle, H. (1993). "Large-eddy Simulation of Turbulent Flow over and Around a Cube in a Plate Channel," in Turbulent Shear Flows (Springer), 8, 155-168. doi:10.1007/978-3-642-77674-8_12

Yakhot, A., Orszag, S. A., Yakhot, V., and Israeli, M. (1989). Renormalization Group Formulation of Large-Eddy Simulations. J. Sci. Comput. 4, 139-158. doi:10.1007/bf01061499

Yin, C., Rosendahl, L., Knudsen Kær, S., and Sørensen, H. (2003). Modelling the Motion of Cylindrical Particles in a Nonuniform Flow. Chem. Eng. Sci. 58, 3489-3498. doi:10.1016/s0009-2509(03)00214-8

Conflict of Interest: The authors declare that the research was conducted in the absence of any commercial or financial relationships that could be construed as a potential conflict of interest.

Copyright (c) 2021 Mankame and Shotorban. This is an open-access article distributed under the terms of the Creative Commons Attribution License (CC BY). The use, distribution or reproduction in other forums is permitted, provided the original author(s) and the copyright owner(s) are credited and that the original publication in this journal is cited, in accordance with accepted academic practice. No use, distribution or reproduction is permitted which does not comply with these terms. 


\section{NOMENCALTURE}

a

$\Delta h_{\text {char }}$

$\Delta h_{\mathrm{pyr}}$

$\dot{m}_{\text {char }}$

$\dot{m}_{\text {pyr }}$

$\dot{q}_{c}$

$\dot{q}_{r}$

$\epsilon$

$\varepsilon_{1}, \varepsilon_{2}, \varepsilon_{3}, \eta$ Quaternions

$\widehat{f}(x, y) \quad$ The normalized number density, NND

$\widehat{z}_{r} \quad$ Major axis of the cylindrical firebrand

$\kappa(\cdot, \cdot) \quad$ The kernel function

$\mathcal{V} \quad$ Volume of the firebrand

$\operatorname{Re}_{h} \quad$ Reynolds number at the reference height $h$

$\operatorname{Re}_{\alpha} \quad$ Reynolds number of the particle in motion

$\omega \quad$ Rotational velocity of the firebrand;

$\phi, \psi, \theta \quad$ Euler angels

$\rho_{\text {gas }} \quad$ Density of the air

$\rho_{p} \quad$ Density of the firebrand

$\stackrel{\sigma}{\rightarrow} \quad$ Stefan-Boltzmann constant

$\vec{F}_{D} \quad$ Drag force

$\vec{F}_{G} \quad$ Force due to gravity

$\vec{F}_{L} \quad$ Lift force

$\vec{T}^{\prime} \quad$ Total torque

$\vec{T}_{\text {hydro }}^{\prime} \quad$ Torque due to hydrodynamic forces

$\vec{T}_{\text {resist }}^{h y d r o}$ Torque due to frictional air resistance
$\vec{V}_{p} \quad$ Velocity vector of the centre of mass of the firebrand

$\vec{V}_{\text {rel }} \quad$ Velocity relative to the flow at the centre of mass of the firebrand

$\vec{x}_{p} \quad$ Position vector of the centre of mass of the firebrand

A Surface area of the firebrand

A Transformation matrix

a radius of a firebrand

$A_{\text {char }} \quad$ Pre-exponential factor for charring

$A_{\text {pyr }} \quad$ Pre-exponential factor for pyrolysis

B Bandwidth

b half length of the firebrand

$C_{D} \quad$ Drag coefficient

$D_{p} \quad$ Diameter of the firebrand

$h \quad$ Reference height

$h_{c} \quad$ Heat transfer coefficient

$I_{x^{\prime}}, I_{y^{\prime}}, I_{z^{\prime}} \quad$ Moment of inertia in the principal axes

1 Length of the firebrand

$m_{p} \quad$ mass of the firebrand

n Total number of firebrands deposited

$T_{\infty} \quad$ Ambient air temperature

$T_{\text {char }} \quad$ Activation temperature for charring

$T_{\text {pyr }} \quad$ Activation temperature for pyrolysis

$T_{p} \quad$ Temperature of the firebrand

$U_{h} \quad$ Inlet velocity at the reference height $h$

$x_{c p} \quad$ Distance between centre of mass and centre of pressure 